Trabajos y Comunicaciones, 2da. Época, No 46, e046, octubre 2017. ISSN 2346-8971

Universidad Nacional de La Plata.

Facultad de Humanidades y Ciencias de la Educación.

Departamento de Historia

\title{
Revolución teórica y epistemología política: las lecciones de Lo Nacional- popular en Bolivia
}

\author{
Theoretical revolution and political epistemology: the lessons of \\ the National-popular in Bolivia
}

\section{Jaime Ortega Reyna *}

* Universidad Nacional Autónoma de México, México | jaime ortega83@hotmail.com

\section{PALABRAS CLAVE}

Zavaleta

Nacional

Popular

Historia

Excedente

Estado

KEYWORDS

Zavaleta

National

Popular

History

Surplus

State

\section{RESUMEN}

Con motivo del treinta aniversario de Lo nacional-popular en Bolivia se realizó una reflexión a propósito de dicha obra que busca profundizar en su sentido epistemológico. Para ello se propone una lectura a partir de conceptos como los de método y ciencia. Se argumenta que la estructura argumental apela más que a un método universal a la conformación de un objeto de estudio específico. La tensión entre universalidad y particularidad se pone a prueba en distintos momentos de la obra, particularmente en la relación entre excedente y Estado. Dicha relación es la constatación de las tensiones al seno de las renovaciones del discurso marxista que acontecieron tras la intervención de Louis Althusser.

\section{ABSTRACT}

On the occasion of the thirtieth anniversary of "The National-Popular in Bolivia", a reflection was made on this work, which seeks to deepen its epistemological sense. For this, emphasis is placed on notions such as method and science. It is argued that the argument structure appeals more than a universal method to the conformation of a specific object of study. The tension between universality and particularity is tested at different moments in the work, particularly in the relation between the concepts of surplus and state. This relation is the realization of the tensions within the renewal of the Marxist discourse that happened after the intervention of Louis Althusser. 
La obra de René Zavaleta se ha convertido en un motivo productivo para la reflexión teórica y empírica contemporánea, particularmente a partir de la emergencia tanto de potentes movimientos indígenas como de formas estatales que reclaman la posibilidad de algun tipo de transformación de las coordenadas políticas reinantes bajo el signo neoliberal. Es por ello que en este texto pretendemos establecer tres vetas que son posibles de ser comprendidas a partir de la dimensión epistemológica de su planteamiento. Es preciso delimitar las líneas principales del aporte de Zavaleta en términos de una epistemología política que opera al seno del marxismo, es decir, que tensiona puntos centrales de la tradición intelectual aludida, llevándolos por veredas escasamente exploradas. Con epistemología política nos referimos a que en la obra de Zavaleta al tiempo que se problematizan los dilemas de la producción de conocimiento, también se encaran las principales coordenadas de la teorización sobre la política, es decir que convoca a la reflexión que en alguna medida cruza por la dimensión de lo estatal, del poder y su relación con la sociedad.

La suya es una construcción teórica que opera sobre ambos carriles: producción de conocimiento y efectos de poder de las estructuras sociales. Es en Lo nacional-popular en Bolivia donde la madurez de su reflexión en ambos registros se anuda de mejor forma, con gran potencialidad y bajo la especificidad de una zona del pensamiento con pretensión universal (la teoría marxista) que busca aprender una realidad socio-política compleja (la boliviana), a partir del seguimiento que hace de la constitución de un fenómeno regional de alta intensidad (lo nacional-popular). En esta triada se juega lo particular, lo singular y lo universal, dimensiones que acompañan gran parte de la constitución conceptual del pensamiento moderno y especificamente de aquel que reclama trazar formas específicas dentro de marcos que se pretenden universales, científicos y totalizantes.

Expondré en tres momentos la reflexión a la que nos convoca de manera diversa la obra del boliviano, partiendo de la premisa de que la obra de Zavaleta puede ser un registro historiográfico sobre el cual trabajar para establecer las coordenadas de un conjunto de debates que ocurrieron en la segunda mitad del siglo XX, pero también que su obra es un apuesta teórica que ha tenido la capacidad de instalarse como un referente que no se limita a su época histórica. Ello nos lleva a retomar la fórmula que Tomás Moulian establecía en su lectura de Lenin, cuando advertía que eran por igual equivocadas las lecturas empiristas tanto como las dogmáticas (Moulian, 1980). El primer tipo de lectura encierra a un autor y su obra en coordendadas particulares, específicas, incapaces de ser universalizadas, es decir, incapaz de ser pensadas más allá de ese tiempo y ese espacio en el que fueron producidas, dejando castrada cualquier posibilidad de utilización productiva de su obra por fuera de ellas. El segundo tipo de lectura alude a la utilización de una obra sin ninguna mediación conceptual, sin trabajo teórico de por medio y se refiere a aquella tradición que traslada cualquier cita a otras coordenadas espacio/temporales como criterio de validez en sí mismas. Separarse y marcar distancia con ambas lecturas no es más que un recuerdo de que el trabajo teórico que se realiza sobre un corpus abreva de una doble dimensión: por un lado la necesidad de su actualización por la vía del diálogo, la interpretación y el aprovechamiento de sus lecciones y por el otro la de situarle en medio de los debates y combates de su tiempo.

Por nuestra parte optamos por una lectura que realice un doble ejercicio: por un lado ubicar las principales discusiones y debates conceptuales que en términos contextuales son hoy ya irrepetibles en tanto que nos encontramos en otro espacio de producción y por otro lado apostamos a capturar el horizonte sentido del combate político que emprende y que en alguna medida sigue vigente al ser parte del específico desarrollo de la forma de la modernidad establecida en gran parte de la América Latina. Esta lectura apuesta a captar el movimiento en la obra, lo que se presenta en estado práctico, no formalizado aún, pero cuya potencia permite abrir campos tanto para el terreno que se comprende entre la producción de conocimientos y aquel que versa sobre la teorización política. En palabras de Elías Palti (2004), captar el movimiento, las tensiones y contradicciones entre las verdades y los saberes del marxismo presentes en Zavaleta.

Me interesa destacar en este artículo como el discurso crítico de René Zavaleta despliega en Lo nacional-Popular en Bolivia el inicio de una alternativa al marxismo de tradición lukacsiana, aunque en tensión con ella y nunca negándola de manera total, pues se mantiene una presencia inconfundible de la categoría de totalidad que se 
habilitó en el marxismo a partir de 1923. Sin embargo de la tensión se obtienen por supuesto conclusiones diversas, algunas versan sobre cierta tendencia de empalmar a Marx con la filosofía hegeliana o la manera en concebir el conjunto de las contradicciones de la sociedad capitalista. Cuando Zavaleta comienza la redacción de este trabajo se ha formado ya como un teórico marxista de gran solidez, la presencia de una lectura atenta y no reduccionista de El Capital se deja sentir con fuerza, además de ello la intención de captar la dimensión "nacionalpopular" en Bolivia lo lleva a confrontar la caja de herramientas de la que dispone. Estas tendencias intelectuales y políticas se harán presentes en el texto que ha cumplido ya 30 años y que sigue resultado crucial al momento de evaluar el estatuo de la producción teórica de la región, así como las lagunas que quedaron ante su incompletud, dada la prematura muerte del teórico boliviano.

Expondremos nuestro plantemiento en tres fases. La primera de ellas avanza sobre la herencia de Zavaleta en nuestros días; el segundo versa sobre el planteamiento epistemológico que circula las primeras páginas de Lo nacional-popular en Bolivia; finalmente quisiera aproximarme de manera sucinta a una temática que se deja ver con poderosos destellos en el caso de este libro, pero que en realidad ordena el conjunto de la obra de Zavaleta: el tema del poder y la constitución de lo político en el mundo mercantil-capitalista. Los últimos dos elementos cierran la pinza de una epistemología política en clave marxista y abre la puerta para la producción "latinoamericana” del marxismo, es decir, que atiende a las especificidades, dinámicas, contradicciones y fuerzas sociales en pugna. Este, como se sabe, es el programa de investigación abierto por José Carlos Mariátegui en los años 20 y que ha sido retomado por numerosos autores, teniendo en Zavaleta uno de los mejores exponentes.

\section{30 años después}

Un renovado interés por la obra de Zavaleta viene gestándose con fuerza durante los últimos años. Autores de tendencias ideológicas tan diversas como Luis Tapia, Elvira Concheiro, H.C.F Mancilla, Mauricio Gil, Lucio Oliver, Luis Antezana, entre otros, han realizado un esfuerzo de lectura productiva de la obra del teórico boliviano: se le asedia como una herencia que se considera invaluable, se le mira positivamente en su planteamiento, pero también se le piensa críticamente. Es posible dialogar con estas aportaciones a partir de su localización en el espectro político. Antezana y Mansilla, por ejemplo, son conocidos y experimentados intelectuales bolivianos que han visto la transformación de las coordenadas ideológicas de manera radical, tomando una posición más bien cautelosa ante el ascenso del movimiento político comandado por Evo Morales, en el plano teórico son estudiosos y críticos de las concepciones de Zavaleta, tal como lo muestra sin cortapisas la obra última de Mansilla (2015). Luis Tapia y Mauricio Gil son intelectuales más jóvenes, ambos han aportado renovadas lecturas a partir de coordenadas menos ideológicas y más teóricas, aunque igualmente ancladas en la historia local, políticamente el primero se ha distanciado del gobierno popular de Morales, sosteniendo una posición de ferrea crítica y el segundo aparece más alejado de la disputa inmediata. En el orden teórico, ambos autores han estudiado la obra de Zavaleta a partir de nociones más finas y contemporáneas, permitiendo la apertura de un horizonte de sentido fresco y novedoso. Finalmente Lucio Oliver y Elvira Concheiro hacen parte de una generación mexicana que interactuó con el Zavaleta maduro, a través de quien leyeron a Marx a Lenin y a Gramsci. Sus proposiciones teóricas abrevan de comprender el problema de la totalidad como el central, tanto en el aspecto social (el "abigarramiento") como en el político (El Estado y su tensa relación con la sociedad civil). Es con estos últimos dos autores con quienes compartimos mayores preocupaciones del orden de la comprensión de la obra. Con ambos sostenemos amplios puntos de contacto y sutiles de diferencia. Compartimos con Concheiro la línea de continuidad entre Marx y Lenin (2016) que se expresa en el análisis político de Zavaleta, en tanto que con Oliver la problemática gramsciana del Estado en su especificidad histórica (2006). Las diferencias son más sutiles y refieren a cierta crítica de las nociones de Lukács que sostengo se dan en "estado práctico" (Althusser, 1969: 143) en el último segmento de su obra.

Además de todos estos textos es preciso señalar que los tiempos que corren, de movilización de sectores que reclaman proyectos "nacional-populares" y de tendencias conservadores, anti-populares y oligárquicas dentro de sectores de la sociedad convocan a una necesaria vuelta de tuerca sobre su obra así como a la problematización de 
los conceptos que nos heredó, de tal manera que sea posible la articulación discursiva que nos dote de consideraciones efectivas para enfrentar una sociedad cambiante, conflictiva, contradictoria.

Aquí se juega, desde el punto de vista de la lectura contemporánea, el punto más candente en la herencia política de Zavaleta. Leído a contracorriente de la descalificación liberal los procesos históricos que conocemos como "populismos realmente existentes" son abordados por Zavaleta en este inconcluso pero potente proyecto de investigación que es Lo nacional-Popular en Bolivia: se trata de rastrear las rutas de la conformación de la dimensión nacional-popular como un elemento constitutivo de las sociedades que comparten rasgos de universalidad (el despliegue de la “potencia económica que lo domina todo” como diría el Marx del 57), pero también características sociales propias, atravesadas por la persistencia de comunidades, formas de producción y distribución no mediadas por el trabajo abstracto, el valor, el dinero y la mercancía, categorías fundamentales del análisis de Marx; así como una situación geo-política en cuyo seno pesan más las tendencias nacionalrevolucionarias que las socialistas. Esta situación marca la tensión no sólo metodológica, sino política, expresada claramente en el asedio de la problemática que Zavaleta enfrentará en los años ochenta, cuando inicia la redacción del trabajo en cuestión siendo ya reconocido como un militante político al tiempo que lo es como un teórico social de gran peso.

Además de los elementos señalados, la problemática de la constitución popular de la nación se despliega en una realidad social cuyas coordenadas se mueven entre la única revolución obrera de la historia de América Latina, el mundo campesino-indígena-comunitario en toda su complejidad sociopolítica y un Estado-nacion que no termina de conformarse con plenitud. Así, la dimensión de apertura se da a partir de la no concreción del Estado-nación "pleno", es decir, competitivo en el mercado mundial, capaz de ser un mediador eficaz entre las clases y los preocesos de expansión del capital. Esta situación no es una anomalía, sino una constante en la historia de nuestra región y Bolivia es quizá la máxima expresión de ello. Las coordenadas políticas se mueven entre la integración al mercado mundial (o en la terminología de Zavaleta la “determinación dependiente”) y Estado no pleno, (la “forma primordial”) que determinarán en gran medida que las opciones socio-políticas no tomen la vía directa del socialismo más que en instantes de lucidez discursiva (como en el caso de Bolivia la juegan las famosísimas Tesis de Pulacayo), sino la de la constitución de alianzas populares que apuntalan la construcción efectiva de lo popular.

Dicha situación confronta el discurso universalista del marxismo con una veta local, eso que Luis Tapia en su original trabajo ha destacado como la centralidad del pensamiento de Zavaleta y que en otros autores más recientes como Diego Giller aparece como una tensión entre lo universal y lo particular, que atravesaría un segmento significativo de su producción. Así, entre la opción teórica y las coordenadas políticas existen una tensión que atraviesa la historia del marxismo producido en América Latina y que Zavaleta enfrenta de una determinada manera.

La sugerente apertura que da Zavaleta es la del estudio de la capacidad de constituir lo nacional a partir del abigarrado mundo de lo popular y en esto se adhiere a una perspectiva que cundió con radicalidad en la segunda mitad del siglo XX, como influjo de procesos descolonización en los planos material e intelectual: la nación no la constituyen las oligarquías ni las aliadas burguesías locales de los poderes dominantes en el mercado mundial. Tampoco es la nación, per se, un elemento perdurable en la historia, es, por el contrario, una conquista, una meta inalcanzable cuyas formas de concreción pueden desvanecerse, un momento de síntesis de los esfuerzos por transformar las condiciones materiales de la existencia. Con Zavaleta la nación es entendida como la primera fuerza productiva, aquella sin la cual no existen el resto de las fuerzas productivas (técnicas principalmente), su existencia permite la coordinación social del trabajo de distintas comunidades y pueblos, que se reconocen como tal en planos simbólicos y que habitan y ocupan un locus espacial determinado.

Nos encontramos en un contexto diamentralmente opuesto al de Zavaleta y sólo los programas políticos con inspiración "nacional-popular" han sido alternativa efectiva, aunque efímera, para oponerse a una situación -la neoliberal- que reordena el mundo en su totalidad. Esta vuelta y problematización de la nación y sobre todo de la constitución popular de la nación no sólo es necesaria, sino que además se presenta como una tarea sumamente 
urgente. Esto es así porque los grupos en el poder, burguesías trasnacionales y oligarquías locales, se han empeñado tanto en la destrucción de la nación y en el languidecimiento de sus estructurales estatales, que suelen ser reducidas a meros comités administrativos de asuntos comunes, parafraseando célebre frase de un texto de 1848. La nación es desarticulada en sus principales puntos de apoyo, son destruidas las comunidades, violentadas las poblaciones, arrasadas milenarias tradiciones productivas y de consumo. Sobre la nación desarticulada operará con plena libertad la forma despótica del valor, de la "auto-regulación” del mercado (es decir, de la ley del más fuerte) y la mercantilización de los mundos de la vida. Por su parte las estructurales estatales son sometidas al escarnio del mercado mundial, cuestionada su legitimidad por abajo y por arriba, la impronta popular que modifica las estructuras del mando político comienzan a ser cuestionadas como inservibles y minusvaloradas como una enfermedad "estatalista" (no es casual que surgieran tendencialmente varias corrientes apostando a “cambiar el mundo sin tomar el poder” en la década pasada).

Con la obra de Zavaleta y otros teóricos de la época podemos captar el momento de una constitución popular de lo nacional en donde el Estado es una poderosa arma que promueve cierta protección a los subalternos, que permite ampliar los derechos, que articula distintas demandas particulares en perspectivas universales; en cambio cuando lo nacional es desarticulado en su sentido popular el Estado se vuelve puro cascarón, un conjunto de instituciones represivas y corruptas. Si la nación es una conquista endeble un Estado con una determinación nacional-popular lo es aún más. Como escribe Zavaleta: "Es verdad que la nación maniquea estatalista es tan falaz como una idea societaria o autonomista o populista de la disección de la política. El Estado puede, en rigor, tener una determinación más nacional-popular o si se quiere más societaria, enfrentando a los sectores menos democráticos de la sociedad (y en los hechos, el Estado ha estado más de una vez por delante de la sociedad)” (Zavaleta, 2008: 47).

Desde este punto de vista volver a Lo nacional-popular es crucial en nuestros días, al menos en América Latina se impone su discusión. Aquella categoría formulada por Gramsci, es la que lo aleja por completo de las interpretaciones del "marxismo occidental" en la clave frankfurtiana, como bien ha investigado Domenico Losurdo en su Antonio Gramsci: del liberalismo al comunismo crítico. Esa diferencia con la perspectiva frankfurtiana es lo que lo ancla a una dimensión histórica y política de un calado sorprendentemente productivo, pues trabaja con los proyectos y programas de las clases populares en su tensión permanente con la estructuras de poder, no por otra razón Zavaleta escribe arrancando su obra: "lo nacional-popular en Bolivia, es decir, la conexión entre lo que Weber llamo democratización social y forma estatal” (Zavaleta, 2008: 9). La perspectiva nacional-popular no permite eludir nuestra historia, ni como clase, ni como etnia, ni como individuos. Esa dimensión histórica no es otra cosa que la condensación de las relaciones y procesos acumulados a lo largo del tiempo que nos sobredetermina y a partir de ellos, se actúa, se realizan ejercicios prácticos y se modifican las formas de lo social. El anclaje que permite la categoría de lo nacional-popular permite tener un Zavaleta produciendo categorías a partir de Gramsci y no sobre Gramsci o retomando y haciendo trabajar productivamente al Lukács de Historia y conciencia de clase del que se alejará. Todo ello nos permite, el día de hoy, tener elementos que permitan ajustar nuestra brújula en unas coordindas políticas más intrincadas y complejas, pero que comparten horizonte con las del teórico boliviano.

\section{Elementos de una epistemología política}

Existe un nivel del discurso que Zavaleta elabora en esta obra que llama poderosamente la atención: la construcción del proceso de producción de conocimiento. Dicha configuración se encuentra expuesta en medio de la elaboración histórica que el autor realiza y convive con ella a lo largo y ancho del texto. Así, Lo nacionalpopular en Bolivia no es sólo un libro sobre la historia de Bolivia, aunque gran parte de su inspiración se encuentre en ella. Tampoco es exclusivamente una consideración sobre aspectos teóricos que circulan con urgencia en el estudio de nuestra América y que privilegia el entendimiento de una dimensión de la movilización social que han impuesto las clases subalternas a lo largo de la historia en sus numerosos intentos por cuestionar las jerarquías del orden social. 
Consideramos que Lo nacional-popular en Bolivia es también un gran ensayo de epistemología política en clave crítica y puede ser considerada crítica aún dentro de las principales claves de interpretación marxista o al menos de algunas que fueron hegemónicas durante la segunda mitad del siglo XX. Con esto queremos señalar que hay un cuestionamiento de los dilemas y dificultades que supone el uso de la caja de herramientas que Marx y el marxismo denominado como no ortodoxo (no reduccionista, no economicista), nos legaron y que en esta obra aparecen asumidos en sus nodos principales, pero también cuestionados. El punto crucial es el problema del carácter universal o a-priori del método de conocimiento. Lo que se cuestionará es justamente su existencia al momento de abordar realidades como la que presenta Bolivia, pero que en el fondo cuestionan algunas de las principales derivas del conjunto del marxismo.

El Zavaleta que se encuentra elaborando esta obra es ya consciente de que las discusiones que cuestionan el paradigma de cientificidad del marxismo en su conjunto obligan a responder realizando un trabajo teórico sobre objetos específicos, es decir, produciendo conocimiento sobre realidades particulares. No se asume la cientificidad sin más, sino que se le pone a prueba y ello implica, por supuesto, mostrar los vacíos teóricos que se presentan cuando el objeto al que se enfrenta no es exactamente el mismo para el que fue pensando en su elaboración inicial. En este sentido es que Zavaleta desarrolla, en lo que habría de ser su principal obra, el cuestionamiento de los aprioris metodológicos y con ello tensionará dimensiones relativas a los conceptos fundamentales de la tradición marxista: formación social, totalidad, estructura, entre otras.

Así, el boliviano entiende bien que hay especificidades, condiciones particulares, determinaciones no comunes, en otras palabras, que hay historia y que en ella se encarna la experiencia diversa de vivir y comprender el mundo. No capitula nunca ante lecturas de Marx en clave de una filosofía de la historia universal, ni de un método válido para su uso en cualquier tiempo y lugar, ni de su validez para construir conocimiento sobre cualquier objeto de investigación. Lo que hace es construir a partir de Marx y más allá de él una metodología para el estudio de Bolivia: construye una reflexión sobre un objeto específico, determinado, con un conjunto de cualidades que no corresponden al ámbito de la "universalidad" abstracta. Si el marxismo es pretensión de conocimiento científico, lo importante no es la dimensión científica pre-establecida, sino su capacidad de traducción en contextos variados, es decir, que su pretensión científica sea actualizable constantemente. Lo nacional-popular en Bolivia es por lo tanto un intento original de plantear el análisis marxista en estado práctico (Althusser, 1969), es decir, trabajando directamente sobre un objeto de estudio e indicando al mismo tiempo algunas notas metodológicas que para nosotros resultan muy sugerentes de ser evaluadas tras las múltiples discusiones desatadas a partir de la crisis del marxismo (Althusser, 1980).

Aproximándonos a las notas metodológicas que se encuentran regadas a lo largo y ancho del texto podemos preguntar ¿Qué conclusión o lección podemos sacar de esta escritura en la que conviven teoría e historia? Existen dos que deben ser señaladas por su importancia y por sus consecuencias y que son la cara ambersa la una de la otra. En primer lugar que el marxismo no es un discurso científico cuya epistemología pertenezca a la lógica de la correspondencia (entre momento económico y político; entre estructuras y super estructuras, entre contenido material y forma social, entre la "esencia" y el "fenómeno") a partir de la cual se desprende un único método; sino lo contrario, que el marxismo es un discurso con pretensión de convertirse en ciencia cuya epistemología es la de la ruptura y su potencia se encuentra en la no correspondencia.

Que el punto crucial del marxismo que Zavaleta practica se encuentra en los momentos de no correspondencia es un punto clave: su corazón no está en la "armonía” ni tampoco en la unidad sin distinción, sino en los momentos de crisis y de ruptura. Con ello apuntala a desmovilizar el discurso sobre el uno totalizante y apuesta a la multiplicidad diferenciada. El concepto central, citado hasta la saciedad entre sus comentaristas, es el de la crisis como método de conocimiento. La crisis es para Zavaleta el momento de ruptura o no correspondencia tanto en el campo de la epistemología, como en el campo de las relaciones de fuerza que se establece al interior de las naciones. Teoría y política encuentran en la crisis su punto máximo de encuentro. Dice Zavaleta de manera inconfundible sobre este aspecto de la crisis, ella es la : “forma de violencia sobre el orden de la rutina” (Zavaleta, 2008: 19). Si la crisis gana tanta relevancia para Zavaleta es porque concurre al momento de la no 
correspondencia, dotando de sentido a los objetos, relaciones, espacios y procesos que se encuentran fuera de la totalización plena, que resultan inconmensurables dentro de la lógica articuladora de lo social, es decir la de la lógica abstraca del valor. Todos esos elementos que aparecen como caóticos e irracionales, adquieren sentido pleno con el advenimiento de la crisis: lección metodológica que Zavaleta ofrece desde la realidad boliviana y que desestabiliza la pretensión de un método marxista válido en cualquier situación. Se trata de la forma en la que la crisis presenta lo inconmensurable, lo que suele aparecer como un resabio del pasado o como un elemento irracional dentro de un mundo plenamente racionalizado, como momentos del proceso de totalización y de destotalización. La crisis impone un ritmo de no correspondencia, dotando ocasionalmente de unidad a aquello que aparece articulado sólo formalmente y mostrando las diferencias, los tiempos y ritmos variados que conviven. La crisis permite entonces captar que la no correspondencia, según el nivel de abstracción que se elija, entre economía y política, entre cultura e idelogía o entre modo de producción y formaciones sociales, es la posibilidad de una construcción metodológica adecuada para Bolivia.

El propio Zavaleta nos había alertado en un texto anterior titulado Las formaciones aparentes en Marx, del dilema que nos dejaba el Prólogo a la Contribución de la crítica de la economía política de 1859 de Marx, en donde se muestra, claramente y con potencia la epistemología de la correspondencia. En ella hay un dominio de la unidad indiferenciada, la plenitud de aquello que Althusser denominó como la "totalidad expresiva" (Althusser, 1969: 105). Lo que está en disputa es la forma de comprensión de la totalidad, por un lado la dinámica expresiva apuntala a que lo universal se muestra indistintamente en lo específico o particular, dándose un fenómeno de correspondencia entre "base y super estructura"; de otro lado la forma que se deja ver tensionadamente en la obra en cuestión muestra lo contrario, es decir que la totalidad tiene ritmos distintos, articulaciones menos profundas o bien momentos de subsunción más profundos de lo que la inmediataz convoca. Así, Zavaleta expresa esta tensión, escribe en un sentido de distancia con respecto a la primera forma: "Totalidad, empero, si bien no es una idea que pueda contener una suma no estructurada, tampoco significa en principio más que eso, que unas parcialidades han tenido que ver en la composición de las otras y que no hay independencia o parcelización con relación a ese fondo histórico-social” (Zavaleta, 2008: 78), pero adelante insiste en una formulación crítica de la segunda noción: "entonces la idea de la simultaneidad de la totalidad debe reemplazar a la existencia de la sociedad como regiones o estrcutura de estructuras” (Zavaleta, 2008: 79). Si la primera cita nos aleja del horizonte lukácsiano y parece colocarse en sintonía con la crítica althusseriana, la segunda desplaza también a esta última. Como reconoce el propio boliviano parecería que la totalidad entra dentro de ese marco de "categorías tan podersas [...] quizá como todas las categorías, escalvas de sus imposibilidades o huecos” (Zavaleta, 2008: 79). Ambas versiones de la totalidad, ya sea la expresiva o la estructural, ambas son escalvas de sus propios dilemas.

Es la Contribución del 59 y su prólogo el máximo ejemplo en donde la correspondencia se impone sobre la crisis y la ruptura, en donde la totalidad aparece en su versión expresiva con mayor radicalidad: ahí la super estructura económica lo domina todo. Sin embargo Zavaleta se distancia también de la versión estructural que Althusser y su escuela plantearon, en donde la totalidad puede tener por momentos segmentos de dispersión y en donde ciertas regiones no aparecen articuladas al conjunto. Para Zavaleta ambas dimensiones son problemáticas si no se discute la posibilidad de ampliar la noción de totalidad y con ella la permanente e infranqueable discusión sobre el peso de lo particular y lo universal, que se encuentran siempre en tensión: la versión expresiva coloca el acento en la simultaneidad y la estructural en los ritmos y distinciones. Ahora nos interesa señalar como el ejercicio crítico sobre el Prólogo del 59 demuestra que la conclusión que se sacó de aquel texto era el claro ejemplo de las formas lineales de comprensión de la historia, de la correspondencia como núcleo epistemológico y sobre todo de la imposibilidad de entender lo específico frente a lo general es decir, la resistencia de lo particular frente a la lógica avasallante de lo universal. Zavaleta mismo nos advertía que se podía traicionar al propio Marx citándolo fielmente.

De aquí derivamos lo que a nuestra consideración es la segunda conclusión importante a la que llega Zavaleta tras el asedio al problema epistemológico. ¿Cómo conocer una formación económica social como la de Bolivia? Esta es su pregunta fundamental y la que permite en realidad cuestionar el horizonte metodológico prevaleciente en el 
marxismo. Sin la enunciación de la pregunta no habría posibilidad de desplazar el problema de la correspondencia al de la crisis. Tampoco de cuestionar el horizonte de la articulación de los modos de producción que excluye una cierta noción de sobredeterminación: "Con justa razón, el término mismo de articulación ha sido después discutido porque sin duda no se trata sólo de un acuerdo entre diversidades, sino de la calificación de unas por otras, de tal suerte que ninguna de ellas mantiene la forma de su concurrencia” (Zavaleta, 2008: 81). Otro tipo de marxismos y otro tipo de marxistas distintos a Zavaleta habrían dado por sentado que aquella formación económica social era simple y llanamente una economía capitalista y que existía, por tanto, una sociedad que respondía por completo a aquella determinación en todos sus niveles (político, cultural, ideológico).

La totalidad en ese otro tipo de marxismo estaba claramente asentada en coordenadas que no se problematizaban y tampoco se cuestionaban el estatuto de un proceso que se asumía como plenamente totalizado. Lo que Zavaleta contribuye a ubicar es de otra manera a ese concepto de totalidad, operando más que como un a-priori en su dimensión procesual en tanto que totalización y por tanto también de las tendencias destotalizantes, así mismo, contribuye a captar la no correspodencia entre los elementos de formación social sumergidos en esos procesos. Es posible pensar con Zavaleta cada uno de los momentos del proceso de totalización de manera independiente, con su propio ritmo, su límite y su espesor específico, justamente en tributo a la concepción althusseriana, pero sin renunciar a la articulación o simultaneidad del tiempo histórico. Zavaleta permite con su obra, cuestianar que el capitalismo existe con plenitud en su dominio, demostrando que existen zonas que desestabilizan esa comprensión y procesos que contribuyen a su destotalización por vías inesperadas. Así, cultura, ideología y política, ganan relevancia frente al frenético dato económico.

Cuando pensamos que Zavaleta parte de una versión alternativa para comprender el marxismo asumimos estas posibilidades de intervención en la teoría. Asume que "la" totalidad no existe en cuanto tal, al menos no como momento cristalizado, sino que existen momentos y procesos de totalización y que en Bolivia aquello aún no era un proceso pleno, es decir, los procesos de destotalización son también importantes en el estudio de cada formación social específica. La totalización es siempre un proceso incompleto, como lo mostraban segmentos relevantes como son el Estado y la construcción de la nación y que Zavaleta claramente establece: "la idea misma de la totalización [...] es algo que no está nunca adquirido para siempre y así la nación puede existir más en el seno de un proyecto o pronóstico colectivo que en el medio de una homogenidad exhausta, y por lo demás, incluso lo que se ha hecho general, tarde o temprano tiende a convertirse en el simbólico conservador de lo particular” (Zavaleta, 2008: 24). Partiendo de ello era posible trazar caminos alternativos útiles para el propio marxismo.

Con Zavaleta se llega a un sendero que se bifurcaba: acepta que Bolivia es una formación social capitalista, pero no podía aceptar que lo era de manera indistinta a otras experiencias históricas, mucho menos a aquellas que remiten a las consideraciones histórica de El Capital. La lectura de este último por parte de Zavaleta resulta crucial para entender la problemática epistemológica que venimos tratando de captar. A partir de la lectura de la obra madura de Marx Zavaleta entenderá hemos dicho antes, los procesos de totalización y destotalización, o que conceptos como nación y formaciones sociales, son categorías que le permiten avanzar y superar las visiones de la epistemología de la correspondencia plena, de la armonía entre estructuras y sobre todo la linealidad de la historia. Abrevaba de una pregunta distinta: ¿Cómo conocemos una sociedad no plenamente totalizada y cómo es que esa no totalización permite la existencia de segmentos de autonomía y diversidad mucho más radicales qué en otras sociedades? Es esta pregunta la que anima su reflexión y de la cual, sin duda, podemos seguir aprendiendo.

\section{Excedente y Estado}

Existe una última dimensión a explorar, la teorización sobre lo estatal que nos ofrece Zavaleta. Paso último éste que me gustaría desplegar para comprender las conclusiones de las elecciones teóricas hechas por el boliviano. El texto que cumple ya 30 años resulta apasionante para quienes estudian la historia de América Latina: Zavaleta nos entrega en Lo nacional-popular en Bolivia una teoría del poder y del Estado relevante para las ciencias sociales 
producidas en América Latina. Como corolario de su crítica epistemológica, asume un conjunto de formulaciones a propósito del Estado, particularmente en su dimensión relacional con respecto a la noción de excedente. Justamente el capítulo primero de la obra que hemos venido utilizando se titula: "La querella del excedente". Zavaleta desmoviliza cualquier pretensión de realizar una operación equivalencia entre la producción de excedente y el desarrollo del Estado a través de sus mediaciones. O para decirlo con otra terminología, apuntala a que la posibilidad de despliegue plena de lo democrático no pase por la inserción al mercado mundial. Política y economía tienen sus propias dimensiones y en gran medida el texto es un apuntalar lo específicamente político sobre lo genericamente económico.

Zavaleta hace crítica del paradigma en donde lo político siempre tiene que enfrentarse con la dimensión económica de manera subordinada y señala que existe, en términos históricos, una tendencia que ha querido desplegar ese binomio (excedente-Estado democrático) de manera paralela, sin realizar un deslinde claro entre una y otra instancia de la totalidad social y asumiendo una articulación determinista o lineal entre ambas nociones. Como podrá observarse aquí se comienza ya a jugar el resultado de la apuesta epistemológica antes presentada. Críticamente señala que la visión que conserva la noción de excedente como la posibilitadora de toda forma de creación de mediaciones democráticas al seno del Estado es una versión conservadora y patrimonialista del origen del poder social. Ello es así porque se asume que el dinero en su pura existencia y presencia genera poder social: para Zavaleta, en cambio, la democracia entendida como autodeterminación (Zavaleta, 2009: 138) nada tiene que ver con el "poder del dinero" (Marx, 1989: 71).

Zavaleta se comporta como un teórico de la sociología histórica al interpretar la historia de América a partir de esta clave comparativa de grandes procesos en donde se juega la democratización social y la capacidad de conformarción de Estados soberanos. Sin embargo antes de hacerlo hace un juicio sobre la constitución conservadora del poder. En una página que me parece crucial se sintetiza con mayores bríos esta teorización sobre el poder, el estado y el dinero y que citamos in extenso:

Por un lado de que el excedente, en efecto, podía generar un estatuto de disponibilidad, de soltura y disposición a lo diferente. Por el otro costado, que podía significar una agresión hacia las cosas y desorganizarlas. Es patente que el excedente por sí minsmo no significa algo sino en relación a la sociedad previa a la que se refiere y por eso se dice que el oro de América empobreció a España. Sea lo que fuere, es cierto que el conjunto del utillaje del Estado moderno tiene algo que ver con la noción de excedente. Si por mediación se entiende la transformación de la furia del oprimido en una parte del programa del opresor, lo cual es después de todo ua relación hegemónica, es obvio que la mediación es tanto más pobislbe cuanto más amplio es el excedente porque representar al Estado ante la sociedad y a la sociedad es algo que contiene dinero, prebendas o gratificaciones. Eso no obstante, el excedente es, en primer término, una medida relativa porque debe ser un excedente respecto a una medida histórico-moral y, en segundo término, el excedente por si mismo no hace sino una relación de especie a género hacia el tema de la disponibilidad. En el implantado dogma del excedente como única forma de disponibilidad posible radica la herencia del fondo mercantilista de la fundación española de América, tributaria siempre de los presupuestos del capital comercial. Debe decirse que si bien la disponibilidad es el momento originario del Estado, por cuanto significa ofrecibilidad o maleabilidad general frente a una proposición, es algo que remata a la vez en una consecuencia dual: conservadora en un sentido, porque la idea de que la riqueza crea poder es una noción vertical, reaccionaria y elitista, en tanto que la disponibilidad generada por actos del pueblo, com voluntad de masa hacia la transformación, es una acto revolucionario (Zavaleta, 2008: 35).

Esta larga cita sirve para demostrar como esta operando la epistemología política de Zavaleta. El descarte que hace entre la adecuación entre excedente y Estado es crucial, para ello recurre al concepto de "disponibilidad" como el momento histórico que posibilita la fundación de orden social nuevo, que desplace al anterior y se establezca como la nueva totalidad. La posibilidad de comprensión de los actos constituyentes o momentos de disponibilidad muestran la capacidad de que una dimensión de la totalidad devenga determinante del proceso de totalización, es decir, que intervenga y sobredetermine a otros elementos de la totalidad que han perdido 
centralidad o capacidad articuladora. Lo que le interesa a Zavaleta es como esa fracción o sección de la totalidad, que solemos llamar política, es capaz de imponer el ritmo de la totalización, incluso por encima del excedente, supuesto articulador o "esencia" de la economía capitalista. El excedente es relevante en la constitución de las relaciones políticas, la suerte de todo Estado depende en gran medida por la manera en que se inserta en el mercado mundial, Zavaleta que es un lector atento de Marx lo sabe perfectamente, sin embargo todo ello no equivale a que en las formaciones sociales como la boliviana esto se cumpla de manera uniforme. Lo que Zavaleta problematiza es el presupuesto de la determinación férrea entre economía y política, que en el lenguaje que el joven Zavaleta (1979) utilizaba, esto se presentaba como una oposición entre "la lógica del mundo y la lógica del lugar”, donde esta última siempre tendía a prevalecer. De lo que se trata es de operar teóricamente al seno de la epistemología del marxismo para comprender como puede ser que una fracción de la totalidad devenga el corazón mismo del proceso de totalización, ahí el "secreto" del entramado que da lugar a la investigación sobre la constitución nacional-popular: si no es la determinación económica representada por el excedente la que ha permitido la totalización (a través de la construcción de mediaciones democráticas y de un Estado racional), aquella posibilidad se encuentra en otro espacio y lugar. En su lenguaje queda planteado así: "Decimos a la vez que no todo excedente genera disponibilidad aunque sí es un elemento favorable para la disponibilidad. Entonces lo que nos interesa es la disponibilidad y no el excedente” (Zavaleta, 2008: 37).

Con respecto a la construcción de una determinación democrática o nacional-popular del Estado, el excedente queda relativizado, queda puesto en suspensión al menos en tanto que los momentos constitutivos se emplazan en la posibilidad de la autodeterminación de la sociedad. Dice Zavaleta que aquí el excedente es tan sólo una medida histórico-moral y no existe plenamente, como esencia última: "Donde no hay disponibilidad no existe ningua función del excedente” (Zavaleta, 2008: 39). Todo ello nos remite a la construcción metodológica que hiciera Louis Althusser cuando señalaba que: "Ni en el primer instantie ni en el último, suena jamás la hora solitaria de la "última instancia" (Althusser, 1979: 93). Con ello se cierra la posibilidad de seguir privilegiando un punto de partida sobre otros o elegir que el fundamento de la totalidad lo posea la economía política, sino en la capacidad de modificación o conquista de éste por parte de una sociedad que se autodetermina: "El excedente por sí mismo no se convierte en material estatal" (Zavaleta, 2008: 41). Se abre también la posibilidad de construcción de alternativas, puesto que el excedente y la inserción al mercado mundial siguen siendo condicionantes de la práctica política (la "lógica del mundo") de conquistarlo por la vía de la constitución popular de la nación (“la lógica del lugar”). Pero dicho elemento sólo puede llegar a ser real cuando se convoca a grandes sectores de la población, es decir, cuando los seres humanos se encuentran en disposición de cambiar sus creencias, pero también cuando aparece la "materia estatal”, es decir, la capacidad de producción de hegemonía, de un nuevo sentido común y de una nueva relación intersubjetiva.

El cambio de paradigma podemos seguir con Zavaleta coloca el énfasis en la capacidad de movilización de las clases, en la capacidad de autodeterminación de las masas, procesos en los que lo importante es la manera en que se llega a la conquista del excedente y no su presencia en cuanto tal, que queda relativizada ante los indicadores de tipo político, en los que se juega una modificación más profunda de la sociedad, como cuando se transforman las creencias y lealtades de los sectores subalternos. Dejar la constitución de lo político como inmediato de la riqueza material no es sino una consideración del "excedente como magia”, o con Marx podríamos hablar del poder que nace de la riqueza como fetiche típico del mundo moderno y sus fantasías. El “excedente como magia” también puede ser pensando como el dominio de las abstracciones, sobre las formas concretas del trabajo y su coordinación, planteándose entonces la tarea de pensar lo específicamente político más allá de la economía.

En la formulación que con Zavaleta venimos criticando, la constitución popular de la nación y la determinación nacional-popular del Estado quedan abatidas, relegadas o francamente neutralizadas. Sin embargo esa consideración podemos captarla incluso en pensadores de una alta intensidad de conocimiento de la obra de Marx, como lo es Bolívar Echeverría, para quien la constitución de la nación es un proceso subsumido plenamente por el capital ante el cual no hay posibilidad de disputa. En la formulación de Echeverría sólo se construyen "naciones de estado" (Echeverría, 1986) entendidas como acuerdo entre propietarios privados atomizados que deciden 
defender un territorio y de ello desprende, en un lenguaje plenamente deudor de la sociología del poder de Max Weber, el concepto de “empresa estatal” (Weber, 2004: 1060). La presencia de las teorizaciónes de Max Weber en pensadores como Zavaleta (es el primer autor en ser citado en Lo nacional-popular en Bolivia), pero también en teóricos latinoamericanos o europeos de la época, como el editor de los Escritos políticos del autor alemán, José Aricó; o en Juan Carlos Portantiero quien se refiriera a Gramsci como el Weber de los sectores subalternos; o en autores italianos que lo incorporaron plenamente (Marramao, 1983) es algo que debe ser estudiado con detenimiento. Zavaleta comparte en un cierto horizonte de época ya no sólo la discusión por el espacio teórico que es la obra de Marx, sino también la de Weber.

Volviendo al tema que nos convoca, en el complejo histórico que Zavaleta comienza a estudiar, lo importante es la posibilidad de la movilización y la politización que permiten el relevo de sentido de las creencias y del sentido común en su conjunto, todo ello permite pensar la construcción de mediaciones que determinen en clave nacional y popular (que sería lo equivalente a la forma democrática europea) al Estado. Es este el centro o efecto político de la investigación que quedó inconclusa, no sólo por la finalización de la vida del autor, sino sobre todo porque el proceso nacional-popular ha sido un constante proceso de totalización y destotalización, sin garantía de un horizonte final de reconciliación o de conquista de un paradisiaco "reino de la libertad", como lo suponía la lectura de Marx en clave de filosofía de la historia. Si en la epistemología hay en Zavaleta una profunda transformación de algunas coordenadas del marxismo, en términos de la política esa transformación se expresa en un horizonte en donde el conflicto y el antagonismo no son superables, sino constituyentes de la forma moderna de pensar lo político y de realizar la querella por el excedente.

La historia de Bolivia que Zavaleta estudia y la que nosotros hacemos para América Latina es esta: la del continuo avance y retroceso de los sectores populares y sus organizaciones en la conquista de la autodeterminación o de su expresión en formas nacional-populares del Estado. Historia inacabada o quizá mejor dicho la historia en cuanto tal, que avanza por senderos diversos, que encuentra su corazón en la movilización de los pueblos, que hace mella de toda forma oligárquica, patrimonial o burguesa de la política, aunque estas vuelvan constantemente reformuladas y con otras máscaras en las que se confunde su rostro. Horizontes todos estos que nos sigue siendo pertinentes, razón por la cual es posible pensar con Zavaleta nuestro tiempo.

\section{Conclusiones}

La poderosa prosa de Zavaleta nos interperla, nos conduce a constituir una metodología distinta en el estudio de los fenómenos "universales” y su relación con la especificidad histórica. Dicha metodología se asienta en una epistemología política distinta. Aquella que pone la crisis política nacional en el centro y que encuentra en los procesos de totalización y destotalización sus principales herramientas teóricas, en tanto que las conceptuales son las enunciadas a partir de las primeras páginas: democratización social y forma estatal. Hemos tenido frente a nosotros, durante 30 años, un documento excelso de la construcción de un conocimiento crítico, materialista y complejo. Volver a dicho texto después de las diversas crísis de paradigmas, de la potencia de un paradigma societal que ordena nuestros distintos mundos de la vida (el mercantil), es una urgencia necesaria. Celebremos pues la vitalidad de las lecciones plasmadas en ella, recordando dos frases de Zavaleta que plantean un horizonte que resiste a los cambios en la historia: "autoconocerse es casi vencer" y sobre todo que "Conocer, en todo caso, no es una mera composición de conceptos: es un acto vital, un desgaste y, en consecuencia, un asunto peligroso, un acto organizativo" (Zavaleta, 2013: 445).

\section{Bibliografía citada}

Althusser, Louis (1969). Para Leer El Capital, México: Siglo XXI. 
Althusser, Louis (1980). “¡Por fin la crisis del marxismo!”, en K.S. Karol et al., Poder y oposición en las sociedades postrevolucionarias, Barcelona: Laia.

Althusser, Louis (1979). La revolución teórica de Marx, México: Siglo XXI.

Concheiro, Elvira, (2016). “El análisis concreto de situaciones concretas: Lenin en la obra de René Zavaleta” en Diego Giller y Hernán Ouviña, René Zavaleta Mercado: pensamiento crítico y marxismo abigarrado, Santiago de Chile: Quimantú.

Echeverría, Bolívar (1986). El discurso crítico de Marx, México: Era.

Mansilla, H.C.F (2015). Una mirada crítica sobre la obra de René Zavaleta Mercado, La Paz: Rincón ediciones.

Marramao, Giacomo (1983). Lo político y las transformaciones, México: Pasado y Presente.

Marx, Karl, (1989). Grundrisse: elementos fundamentales para la crítica de la economía política, México: Siglo XXI.

Moulian, Tomás (1980). “Cuestiones de teoría política: una crítica de Lenin”, Documentos de Trabajo, No. 105, FLACSO: Santiago de Chile.

Oliver, Lucio (2006). “René Zavaleta ante la especificidad latinoamericana del Estado y la política”, en Maya Aguiluz y Norma de los Ríos, René Zavaleta Mercado: ensayos, testimonios y re-visiones, México: PPELA-Miño y Dávila.

Palti, Elías J (2004). Verdades y saberes del marxismo, Buenos Aires: FCE.

Weber, Max (2004). Economía y sociedad, México: FCE.

Zavaleta, René (1979). El poder dual en América Latina, México: Siglo XXI.

Zavaleta, René (2008). Lo nacional-popular en Bolivia, La Paz: Plural.

Zavaleta, René (2009). “Cuatro conceptos de la democracia” en La autodeterminación de las masas [Antología de René Zavaleta], Buenos Aires: CLACSO.

Zavaleta René (2013). “Las formaciones aparentes en Marx” en Obra completa. Tomo II: Ensayos 1975-1984, La Paz: Plural. 